\title{
An Intervention Study on Velocity, Agility and Jump Ability in Youth Basketball Players in Albania
}

\author{
Spahi, A. \\ Jarani, J. \\ Bilali, A. \\ Sports University of Tirana, Albania, Corresponding author; Andi Spahi, Sports University of Tirana, Tirana, Albania \\ Email: andispahi@gmail.com
}

\section{Doi:10.5901/mjss.2015.v6n4s1p504}

\begin{abstract}
Introduction. An intervention study on youth basketball players during a 6-month fitness training aiming to assess and compare the performance on velocity, agility and jump ability on a frequency twice weekly was performed in Tirana, Albania. Methods. Twenty-eight youth (male) basketball players (age range 17-18 years) participated in this intervention study. They were assessed Pre and Post training through; velocity $10 \mathrm{~m}$ and $20 \mathrm{~m}$, agility test $10 \times 5 \mathrm{~m}$ and drop jump test. The intervention study lasted 6 months (twice weekly) on a fitness gym (strength training). The duration for each training set had lasted for each 45 min (8 fitness machines was used). Results. Results showed statistical significant improvement with regard to $F$ max (kN), $F$ $\max (\mathrm{kg} \mathrm{N})$ and power $(\mathrm{kg} \mathrm{W})$ at $p$ level $=0.05$. No statistical improvement were found for contact time and air time between pre and post measurement ( $p=0.09 ; p=0.66)$. Also it was statistical significant improvement with regard to velocity $10 \mathrm{~m}$ (seconds), velocity $20 \mathrm{~m}$ (seconds) and agility $10 \times 5 \mathrm{~m}$ (seconds) at $p$ level $=0.05$. Conclusion. The intervention performed in this study was successfully with regards to velocity, agility and jump performance. This study will be a powerful tool for the coaches in order to improve the performance of their players through fitness training in youth.
\end{abstract}

Keywords: youth, fitness training, velocity, jump

\section{Introduction}

Contemporary basketball demands greater quantity of velocity, force, dexterity, coercion, stamina and also, flexibility. Along with these requirements body structure and muscular physique, has substantial importance regarding this sport. Strength training affect better in decreasing injury in athletes (McKeag, 2003), and most of the time affects improving motor performance (Fleck \& Kraemer, 2004; Micheli, \& Purcell, 2007) so is also a very important part of basketball off-season programs (Fulton, 1992, Price, 2006). The importance of coming up with qualitative conditioning schedules founded on the particular physiological requirements of every sport is viewed as a key element to success (Gillam 1985; Taylor 2003 \& 2004). As stated by Vanttinen and his associates (2011), that aerobic exercising helps in reducing body tallow, fat size and enhance slim body mass. There is a sturdy connection between body structure and aerobic abilities. When body mass and fat heft rises, aerobic capacity seems to drop (Sotiropoulous, et al., 2009). Nevertheless, reduction of fat mass and growth of lean body mass evidently enhance VO2 maximum (Macpherson, et al., 2011). The recognized advantages of performing sports distinct training is that the training will shift better into the sportsmen competitive habitat and that the greatest exercising profits happen when the exercising impetus simulates the particular motion patterns and physiological requirements of the sport (McArdle, Katch and Katch 1996). Correctly designed and competently supervised, fitness training programs carry no extra overload on young athletes' skeletal muscles as proved by the absence of injury during the training program. An intervention study on youth basketball players during a 6-month fitness training aiming to assess and compare the performance on velocity, agility and jump ability on a frequency twice weekly was performed in Tirana, Albania.

\section{Methods}

A total of twenty eight (28) male youth basketball players were selected in Tirana the capital city of Albania. These participants were randomly selected from a pool of 120 youth basketball players regularly participated in national youth basketball championship. The mean age of the selected players was $17.4 \pm 1.4$. The selected players had $2.8 \pm 1.1$ years of playing experience and regularly participate in training prior to the commencement of this study. Four tests were made by the participant; velocity $10 \mathrm{~m}$ and $20 \mathrm{~m}$, agility test $10 \times 5 \mathrm{~m}$ and drop jump test. 
Table 1. Descriptive Statistics for participant

\begin{tabular}{lccccc}
\hline \hline & $\mathrm{N}$ & Min & Max & Mean & Std. Dev \\
\hline Age & 28 & 16.9 & 17.8 & 17.4 & 1.4 \\
Body Mass & 28 & 60.0 & 84.0 & 72.5 & 8.0 \\
Body Height & 28 & 1.71 & 1.86 & 1.79 & 0.05 \\
BMl & 28 & 19.9 & 24.4 & 22.5 & 1.6 \\
\hline \hline
\end{tabular}

\section{Intervention}

The Intervention on youth basketball players lasted for 6 months. The total frequency was twice weekly with a duration per session $45 \mathrm{~min}$. The training intervention was performed on the fitness gym (strength training) placed in the gym of Sports University of Tirana. Strength exercise was performed using 8 machines while the agility exercises (speed and agility exercises) were lasted with duration 10- 15 min (4-6 exercises).

\section{Protocols of the Tests Performed}

\subsection{Drop jump test}

The aim of this test is to find the ideal high of jump for the test. This test was performed at laboratory equipment (Force platform Leonardo Mechanography) placed at Sport University of Tirana. The subject salt on the bench of $40 \mathrm{~cm}$ and put the feet close to the border and the hands on the hips. Put the fee tforward on the bench and let yourself to fall on the platform (warning, you do not have to jump down, but let fall). Touch the ground with both feet and react immediately jumping upwards. (Warning, make sure that the jump is upward and not forward). The test will measure 3 times and will take the best measurement that have less time contact on the platform after the fall.

\subsection{Velocity}

The tests were performed as follows; put the port of timing system brower 10 and 20 meters between them. The athletes stand $10 \mathrm{~cm}$ before the IR (infra red) line of the port of Timing system, and starts whenever he feels ready to start. In the same time we can measure the time and the velocity without making any calculation. The timing system brower will measure very quickly and a lot of athletes without losing time.

\subsection{Agility}

Shuttle run $10 \times 5$ mtest (Eurofit., 1993) to assess the speed and agility of the lower limbs. Marker cones and/or lines are placed five meters apart. The child starts with a foot at one marker. When instructed by the timer, the child runs to the opposite marker, turns and returns to the starting line. This is repeated five times without stopping (covering 50 meters total). At each marker both feet must fully cross the line. The time taken to complete 50 meters course is recorded. for this test equipment are required: stopwatch, measuring tape, marker cones, and a flat non-slip surface.

\subsection{Statistical Analysis}

The data were gathered and organized in excel file. Than were transferred and analysis using statistical package SPSS (Windows version). Initially, we calculated the descriptive statistics (means and SDs) of every parameter.. It was used ANOVA test for pre- post comparison for each variables where a high level of significance was adopted ( $p \leq 0.005)$. Only those analyses during comparison $(p \leq 0.005)$ were considered statistically difference for two time measurement. SPSS statistical program was used for calculation of the results obtained from this research study.

\section{Results}

Descriptive statistics for drop jump test showed that at pre and post measurement; $F$ max was (3.3 and $3.6 \mathrm{kN}$ ), 43.4 and 48.9 $\mathrm{kgN}$; power 31.2 and $34.2 \mathrm{kgW}$; contact time 0.3 and $0.3 \mathrm{~s}$; air time 0.4 and $0.5 \mathrm{~s}$. (table 2). 
Table 2. Descriptive Statistics for Drop jump test at pre and post measurement

\begin{tabular}{lcccccccc}
\hline \hline & & Mean & Std. Dev & Std. Error & \multicolumn{2}{c}{$95 \%$ Cl } & Min & Max \\
& & & & & Lower Bound & Upper Bound & \\
\hline F max (kN) & Pre & 3.262 & 0.527 & 0.215 & 2.709 & 3.815 & 2.700 & 3.900 \\
& Post & 3.620 & 0.504 & 0.206 & 3.091 & 4.149 & 3.220 & 4.540 \\
& Total & 3.441 & 0.526 & 0.152 & 3.107 & 3.775 & 2.700 & 4.540 \\
F max (kg N Kg) & Pre & 43.868 & 5.995 & 2.448 & 37.577 & 50.160 & 32.000 & 48.080 \\
& Post & 48.875 & 7.895 & 3.223 & 40.590 & 57.160 & 36.000 & 59.740 \\
& Total & 46.372 & 7.177 & 2.072 & 41.812 & 50.932 & 32.000 & 59.740 \\
Power (kg W Kg) & Pre & 31.182 & 3.596 & 1.468 & 27.408 & 34.955 & 27.390 & 36.760 \\
& Post & 34.167 & 3.430 & 1.400 & 30.567 & 37.767 & 30.000 & 38.000 \\
& Total & 32.674 & 3.695 & 1.067 & 30.326 & 35.022 & 27.390 & 38.000 \\
Contact time (tc) $)$ & Pre & 0.291 & 0.058 & 0.024 & 0.230 & 0.352 & 0.240 & 0.400 \\
& Post & 0.337 & 0.055 & 0.022 & 0.279 & 0.395 & 0.260 & 0.410 \\
& Total & 0.314 & 0.059 & 0.017 & 0.276 & 0.352 & 0.240 & 0.410 \\
Air time (ta) & Pre & 0.445 & 0.106 & 0.043 & 0.334 & 0.556 & 0.230 & 0.510 \\
& Post & 0.467 & 0.053 & 0.022 & 0.411 & 0.522 & 0.400 & 0.560 \\
& Total & 0.456 & 0.081 & 0.023 & 0.405 & 0.507 & 0.230 & 0.560 \\
tal tc & Pre & 1.520 & 0.410 & 0.167 & 1.090 & 1.950 & 0.990 & 1.980 \\
& Post & 1.508 & 0.363 & 0.148 & 1.128 & 1.889 & 1.130 & 2.110 \\
& Total & 1.514 & 0.369 & 0.107 & 1.280 & 1.749 & 0.990 & 2.110 \\
\hline \hline
\end{tabular}

Table 3 shows the results from ANOVA statistics from pre and post measurement for drop jump test variables. Results showed statistical significant improvement with regard to $F \max (\mathrm{kN}), F \max (\mathrm{kg} \mathrm{N})$ and power $(\mathrm{kg} \mathrm{W})$ at $p$ level $=0.05$. No statistical improvement were found for contact time and air time between pre and post measurement $(p=0.09 ; p=0.66)$.

Table 3. ANOVA comparison for Drop jump test at pre measurement

\begin{tabular}{|c|c|c|c|c|c|}
\hline & & S Sum of Squares & Mean Square & $\overline{\mathrm{F}}$ & Sig. \\
\hline \multirow[t]{3}{*}{$\mathrm{F} \max (\mathrm{kN})$} & Between Groups & 0.385 & 0.385 & 1.449 & 0.056 \\
\hline & Within Groups & 2.658 & 0.266 & & \\
\hline & Total & 3.043 & & & \\
\hline \multirow[t]{3}{*}{$\mathrm{F} \max (\mathrm{kg} \mathrm{N} \mathrm{Kg})$} & Between Groups & 75.2 & 75.2 & 1.53 & 0.044 \\
\hline & Within Groups & 491.369 & 49.137 & & \\
\hline & Total & 566.57 & & & \\
\hline \multirow[t]{3}{*}{ Power (kg W Kg) } & Between Groups & 26.731 & 26.731 & 2.165 & 0.052 \\
\hline & Within Groups & 123.489 & 12.349 & & \\
\hline & Total & 150.219 & & & \\
\hline \multirow[t]{3}{*}{ Contact time (tc) } & Between Groups & 0.006 & 0.006 & 1.97 & 0.091 \\
\hline & Within Groups & 0.032 & 0.003 & & \\
\hline & Total & 0.038 & & & \\
\hline \multirow[t]{3}{*}{ Air time (ta) } & Between Groups & 0.001 & 0.001 & 0.198 & 0.666 \\
\hline & Within Groups & 0.07 & 0.007 & & \\
\hline & Total & 0.071 & & & \\
\hline \multirow[t]{3}{*}{ ta/ tc } & Between Groups & 0 & 0 & 0.003 & 0.959 \\
\hline & Within Groups & 1.497 & 0.15 & & \\
\hline & Total & 1.498 & & & \\
\hline
\end{tabular}

Descriptive statistics velocity and agility test showed that at pre and post measurement; sprint 10m was (1.89 and 1.81 seconds), sprint $20 \mathrm{~m}$ ( 3.5 and 3.3 seconds) and agility power was 14.1 and 13.6 seconds (table 4 ). 
Table 4. Descriptive statistics for velocity and agility at pre and post measurement

\begin{tabular}{llccccccc}
\hline \hline & & Mean & Std. Dev & Std. Error & \multicolumn{2}{c}{$95 \%$ Cl } & Min & Max \\
& & & & & Lower Bound & Upper Bound & \\
\hline Sprint 10m duration & Pre & 1.89 & 0.05865 & 0.02394 & 1.8284 & 1.9516 & 1.8 & 1.97 \\
& Post & 1.8167 & 0.05538 & 0.02261 & 1.7586 & 1.8748 & 1.72 & 1.88 \\
& Total & 1.8533 & 0.06651 & 0.0192 & 1.8111 & 1.8956 & 1.72 & 1.97 \\
Sprint 10m velocity & Pre & 19.0167 & 0.61779 & 0.25221 & 18.368 & 19.665 & 18.2 & 20 \\
& Post & 18.95 & 1.24378 & 0.50777 & 17.645 & 20.2553 & 17.3 & 20.8 \\
& Total & 18.9833 & 0.93695 & 0.27047 & 18.388 & 19.5786 & 17.3 & 20.8 \\
Sprint 20m duration & Pre & 3.4967 & 0.17143 & 0.06998 & 3.3168 & 3.6766 & 3.23 & 3.74 \\
& Post & 3.3 & 0.13476 & 0.05502 & 3.1586 & 3.4414 & 3.04 & 3.4 \\
& Total & 3.3983 & 0.17933 & 0.05177 & 3.2844 & 3.5123 & 3.04 & 3.74 \\
Sprint 20m velocity & Pre & 21.1667 & 0.84774 & 0.34609 & 20.277 & 22.0563 & 20.2 & 22.3 \\
& Post & 21.3 & 0.87178 & 0.3559 & 20.385 & 22.2149 & 20.5 & 23 \\
& Total & 21.2333 & 0.82278 & 0.23752 & 20.711 & 21.7561 & 20.2 & 23 \\
Agility 10x5m duration & Pre & 14.145 & 0.4807 & 0.19624 & 13.641 & 14.6495 & 13.57 & 14.94 \\
& Post & 13.64 & 0.41497 & 0.16941 & 13.205 & 14.0755 & 13.1 & 14 \\
& Total & 13.8925 & 0.50285 & 0.14516 & 13.573 & 14.212 & 13.1 & 14.94 \\
Agility 10x5m velocity & Pre & 19.455 & 0.89793 & 0.36658 & 18.513 & 20.3973 & 18.47 & 20.86 \\
& Post & 18.855 & 0.41264 & 0.16846 & 18.422 & 19.288 & 18.27 & 19.46 \\
& Total & 19.155 & 0.73625 & 0.21254 & 18.687 & 19.6228 & 18.27 & 20.86 \\
\hline \hline
\end{tabular}

Table 5 shows the results from ANOVA statistics from pre and post measurement for velocity and agility tests variables. It was statistical significant improvement with regard to velocity $10 \mathrm{~m}$ (seconds), velocity $20 \mathrm{~m}$ (seconds) and agility $10 \times 5 \mathrm{~m}$ (seconds) at p level $=0.05$.

Table 5. ANOVA comparison for velocity and agility at pre and post measurement

\begin{tabular}{|c|c|c|c|c|c|}
\hline & & Sum of Squares & Mean Square & $\mathrm{F}$ & Sig. \\
\hline \multirow[t]{3}{*}{ Sprint $10 \mathrm{~m}$ duration } & Between Groups & 0.016 & 0.016 & 4.959 & 0.05 \\
\hline & Within Groups & 0.033 & 0.003 & & \\
\hline & Total & 0.049 & & & \\
\hline \multirow[t]{3}{*}{ Sprint $10 \mathrm{~m}$ velocity } & Between Groups & 0.013 & 0.013 & 0.014 & 0.909 \\
\hline & Within Groups & 9.643 & 0.964 & & \\
\hline & Total & 9.657 & & & \\
\hline \multirow[t]{3}{*}{ Sprint $20 \mathrm{~m}$ duration } & Between Groups & 0.116 & 0.116 & 4.881 & 0.052 \\
\hline & Within Groups & 0.238 & 0.024 & & \\
\hline & Total & 0.354 & & & \\
\hline \multirow[t]{3}{*}{ Sprint $20 \mathrm{~m}$ velocity } & Between Groups & 0.053 & 0.053 & 0.072 & 0.794 \\
\hline & Within Groups & 7.393 & 0.739 & & \\
\hline & Total & 7.447 & & & \\
\hline \multirow[t]{3}{*}{ Agility $10 \times 5 \mathrm{~m}$ duration } & Between Groups & 0.765 & 0.765 & 3.794 & 0.05 \\
\hline & Within Groups & 2.016 & 0.202 & & \\
\hline & Total & 2.781 & & & \\
\hline \multirow[t]{3}{*}{ Agility $10 \times 5 \mathrm{~m}$ velocity } & Between Groups & 1.08 & 1.08 & 2.212 & 0.168 \\
\hline & Within Groups & 4.883 & 0.488 & & \\
\hline & Total & 5.963 & & & \\
\hline
\end{tabular}

\section{Discussion}

The result of the study showed that six weeks of basketball specific endurance circuit training intervention manifested significant improvements. Results showed statistical significant improvement with regard to $\mathrm{F} \max (\mathrm{kN}), \mathrm{F} \max (\mathrm{kg} \mathrm{N})$ and power $(\mathrm{kg} \mathrm{W})$ at $\mathrm{p}$ level $=0.05$. No statistical improvement were found for contact time and air time between pre and post measurement $(p=0.09 ; p=0.66)$. The conclusion of this study agrees with the finding from a study by Adams et al. (1992). They found that participants who used a combined plyometrics and squat training program had more significant increases in vertical jump height than participants who trained with squats or plyometric alone.

Also it was statistical significant improvement with regard to velocity $10 \mathrm{~m}$ (seconds), velocity $20 \mathrm{~m}$ (seconds) and 
agility $10 \times 5 \mathrm{~m}$ (seconds) at $p$ level $=0.05$. This clearly indicates that after adjusting pretest scores, there was a significant difference between the groups on adjusted pre and post-test scores. In research that study percentage of body grease, lean body heft and fat mass displayed no crucial variation as a result of basketball particular endurance round exercising. In general terms aerobic training lowers the percentage of body tallow, fat mass and enhance lean body mass (Vanttinen, 2011). Fatouros et al. (2000) found that the combined training group (plyometric and strength training) showed signs of improvements in their vertical jump performance and leg strength that were significantly greater than the improvements in the other two training groups (plyometric training and weight training). It is also highlighted that when body load and fat mass rises the aerobic ability seems to fall (Sotiropoulous, 2009). Strength training affect better in decreasing injury in athletes (McKeag, 2003), and most of the time affects improving motor performance (Fleck \& Kraemer, 2004; Micheli, \& Purcell, 2007) so is also a very important part of basketball off-season programs (Fulton, 1992, Price, 2006)

\section{Conclusion}

The intervention performed in this study was successfully with regards to velocity, agility and jump performance. This study will be a powerful tool for the coaches in order to improve the performance of their players through fitness training in youth.

\section{References}

Adams, K., O'Shea, J.P., O'Shea, K.L., \& Climstein, M. (1992). The effect of six weeks of squat, plyometric and squat-plyometric training on power production. Journal of Strength and Conditioning Research, 66, 36-41.

Balabinis, C.P., Psarakis, C.H., Moukas, M., Vassiliou, M.P., Behrakis, P.K. (2003). Early phase changes by concurrent endurance and strength training. J Strength Cond Res, 17(2): 393-401.

Chittibabu, B. (2013). Effect of handball specific repeated-sprint training on aerobic capacity of male handball players. International journal of Physical education, Fitness and Sports, 2(4): 4-7.

Eurofit. (1993). Eurofit Tests of Physical Fitness.Strasbourg, 2nd Edition.

Gillam, G. (1985). Physiological basis of basketball bioenergetics. NSCA Journal, 6: 44-71.

Fatouros, I.G., Jamurtas, A.Z., Leontsini, D., Kyriakos, T., Aggelousis, N., Kostopoulos, N., \& Buckenmeyer, P. (2000). Evaluation of plyometric exercise training, weight training, and their combination on vertical jump performance and leg strength. Journal of Strength and Conditioning Research, 14, 470-476.

Fleck, S.J, \& Kraemer, W.J. (2004). Designing resistance training programs - 3rd edition. Champaign, IL: Human Kinetics.

Fulton, K.T. (1992). Off-season strength training for basketball. National Strength \& Conditioning Association Journal, 14, 31-34.

Helgerud, J., Engen, L. C., Wisloff, U., and Hoff, J. (2001). Aerobic endurance training improves soccer performance. Medicine and Science in Sports and Exercise, 33(11): 1925-1931.

Lawson, E. (2001). Incorporating sports-specific drills into conditioning. In B. Foran (Ed.), High performance sports conditioning (pp. 215266). Champaign, IL: Human Kinetics.

McArdle, D.M.; Katch, FI. \& Katch, V.L. (1996). Exercise physiology: energy, nutrition and human performance (5th Ed.). Philadelphia, PA: Lippincott Williams and Wilkins.

McMillan K., Helgerud, J., Macdonald, R., and Hoff, J. (2005). Physiological adaptations to soccer specific endurance training in professional youth soccer players. British Journal of Sports Medicine, 39:273-277.

McKeag, D. (2003). Basketball: Olympic handbook of sports medicine. Malden, MA: Blackwell Publishing.

Micheli, L., \& Purcell, L. (2007). The adolescent athlete: A practical approach. New York, NY: Springer.

Price, R.G. (2006). The Ultimate Guide to Weight Training for Basketball - 4th edition. Cleveland, OH: Price World Enterprises.

Sotiropoulos, A., Travlos, A.K., Gissis, I., Souglis, A.G., Grezios, A. (2009). The effect of a 4-week training regimen on body fat and aerobic capacity of professional soccer players during the transition period. J Strength Cond Res, 23(6): 1697-703.

Taylor, J. (2003). Basketball: applying time motion data to conditioning. Strength and Conditioning Journal, 2: 57-64.

Taylor, J. (2004). A tactical metabolic training model for collegiate basketball. Strength and Conditioning Journal, 5: 22-29.

Vänttinen, T., Blomqvist, M., Nyman, K., and Häkkinen, K. (2011). Changes in body composition, hormonal status, and physical fitness in 11-, 13-, and 15-year-old Finnish regional youth soccer players during a two-year follow-up. J Strength Cond Res, 25(12): 33423351. 